\title{
The Effect of Emotional Resilience on Job Performance of Executives in Selected Private Sector Organizations in Sri Lanka
}

\author{
H. L. Ekanayake ${ }^{1}$ and P. N. Gamage ${ }^{2}$ \\ ${ }^{1,2}$ Department of Human Resource Management, \\ Faculty of Commerce and Management Studies, University of Kelaniya, Sri Lanka \\ ${ }^{1}$ harshikandy94@gmail.com, ${ }^{2}$ prasadini@kln.ac.lk
}

\begin{abstract}
When operating in a complex work environment, it is obvious that the companies will have to face many challenges and changes. This will create a stressful work environment for the employees who are working. It is mandatory to have more resilient employees, who can quickly recover from the stress, as it affects directly to their low performance. The sole purpose of this study is to identify the impact of the ability of the individuals to quickly bounce back from the stressful situations and how does it impact on employees' work performance.
\end{abstract}

The study was an explanatory cross-sectional in nature. The simple random sampling technique has been used as the sampling method. The researcher distributed a questionnaire among the participants in the selected sample which encompasses 74 respondents from three selected companies where two companies are possessing 25 employees each and 24 employees from another company consists of executive level employees. In addition, the items of the questionnaire were extracted from a standard and well-tested measurement scale. Descriptive statistics, correlation and regression were used to analyze the collected data set in order to get in to a statistically supported conclusion. The findings have revealed that there is a significant relationship between the emotional resilience and the employee performance and also there is a impact comes from the employees' emotional resilience on the employees' work performance and the results depicted that $24.4 \%$ of an impact comes from emotional resilience. The findings of the research study will be beneficial for the companies who will hire more resilient individuals, who can quickly adapt and who can quickly recover from the hectic situations.

\section{Keywords: Emotional Resilience, Employee performance}

\section{Introduction}

The dynamic business environment is a challenge and it has become one of the norms for every organization all over the world (Shin, Taylor, and Seo 2012, as cited in Bardoel et al., 2014). With the extreme competition, they have to enhance their overall performance as well. Therefore, organizations need to navigate their businesses and the employees in order to survive. The competition and the unbearable changes can create an excessive stress in the workplace. It is obvious that the employees will have to experience the negative feelings such as fatigue and anger along with the stress especially when they work continuously in all seven days. The inability to recover from the pressure will diminish the overall performance of the 
organization. This is why; most of the organizations nowadays look for the individuals who can quickly bounce back from the traumatic situations. They look for a particular trait of individuals that creates such an ability, which is called as the emotional resilience. This research study mainly focuses on to identify the impact comes from the emotional resilience on the employees' work performance. Employees supposed to be the life blood of the organization and they ensure the health of the workplace. Resilient employees will improve the overall organizational resilience where it enhances the ability of the organizations to recover promptly in adverse circumstances. This particular trait of individuals improves the tolerance level of the employees and they have to be more positive in the areas of thinking and work attitudes. Most importantly they demonstrate more effective human responses in front of the adverse instances. This specialty will lead them to bounce back from unpleasant conditions faster than the employees who are not resilient.

The level of resilience can be differing from person to person, as their inner genetic factors are different. Moreover, the gender, age, work experience, environment they work, the social groups they interact, and the mental status currently they are in also different from person to person. Empirical evidence suggested that the resilience can be affected by various factors such as genes, age, gender, work experience, and the companies' HR practices. The personnel resilience has been identified as a stable trait by the traditional view; even so most of the recent researchers have identified it as an outcome of the processes that occur when people respond to the stressful instances. Organizations' success depends on how well their employees perform productively to achieve the defined goals and objectives.

Moreover, as the employees play a key role in ensuring the survival and the effective functioning of the organization in this extremely competitive environment, nurturing the employees' performance has taken an increasing attention nowadays since it generates many favorable outcomes to the organization. Empirical evidence has emphasized that, every employee is expected to perform effectively and efficiently in order to achieve the organizational goals and objectives (Kumari \& Sangwan, 2015) as performance has become the key in nurturing the organizational productivity. Other than the productivity, the organizations also can enhance the customer satisfaction, organizational development and growth with the well performed employees (Pradhan \& Jena, 2017). Therefore, the current study has focused on identify, how those performance of the employees are affected by the concept of emotional resilience. As in case if the employees take too much of time to recover from the hectic incidents, they might not be able to work efficiently like they usually do because of the constant worry they experience and it will create an unnecessary cost to the company as well.

There are number of studies relating to the stress, but the concept of how quickly a person can bounce back from the stress can be identified as a very rare area for the research field. Hence, 
the current study provides a sensible insight about the association between emotional resilience and employees' work performance.

\section{Context of the Study}

The population of the research consists of the executive level employees in selected private sector companies in Sri Lankan context and the current researcher has selected three organizations. In general, the public sector of a country contributes to generate more infrastructure facilities, but to strengthen the country's economy there is a need of having an energetic private sector within a country as well. In the current context, the average investment made for the GDP in Sri Lanka for the last five years (since 2013) revealed that the country's investment to the GDP was $31 \%$. The public sector investment was $5 \%$ and the foreign direct investment was recorded as $2 \%$. Rest of the $24 \%$ made up from the private sector investments. The aforesaid information clearly emphasized that the importance of the private sector for an economy. Apart from the government sector organizations, private sector creates more job opportunities, embrace new technology and it also generates foreign income as well and because of the competition available, many private sector organizations have to work 24/7continuously. High workload essentially creates a stress for the people who are working. Therefore, it is important to consider about the level of resilience of the employees in the organization as their productive performance is highly significant for the success of the organization.

\section{Statement of Problem}

If the organizations are unable to assist their employees to bounce back from the adversarial situations, it will create a cost to the company and that can be either a hidden or an apparent. Many organizations all over the world have witnessed the concerns they face because of having lack of resilient individuals. The Compendium of worker' compensation statistics, Australia 2007 -2008 revealed that the average of 10.9 weeks of lost time to injuries and with a median payment of $\$ 14,300$ per person occurred due to the excessive work stress (Resilience in Organizations, 2011).

Because of the high level of stress, many countries have found that there has been a substantial increase in the area of work related stress injuries. Moreover, the estimated cost because of this to the Australian community is not less than \$AUD 25 billion annually. Apart from that, the European Agency for Safety and Health at Work also reported that in the year of 2005, one in every four workers affected by it and that $50 \%$ to $60 \%$ of all lost working days were related to it. Furthermore, they had to suffer from a financial cost and it was not less than $€ 22$ billion. In United States' $0.3 \%$ of the gross domestic product was also affected by these, stress related effects and it was not less than US\$ 45 billion (Winwood, McEwen, \& Colon, 2013). Furthermore, employees' association in traumatic events created a number of concerns and it was one of the major problems for the union and the managers in Canada Post Pacific Region. According to the anecdotal data, it was stated that lack of resilience lead employees to experience high 
level of stress and it was taking a substantial amount of time to recover from such events (Freeman \& Carson, 2006).

When it comes to the Sri Lankan context, emotional resilience at work has taken a lessening attention in Sri Lankan research field. A study has conducted in Sri Lankan context, as Psychosocial Assessment of the War Affected Northern and Eastern Provinces of Sri Lanka: Distress and Growth Post-War and the study further revealed that the sectors as if employment, livelihood participation, and social interactions are being affected by the psychological issues relating to the above situation (UsoofThowfeek, 2018). These incidents prove that the stress related instances create an unnecessary and an unbearable cost to the organizations and sometimes for the country as a whole where it is common for the Sri Lankan context as well. Companies nowadays look for the individuals who can effectively deal with the stress and who can quickly recover. That ability of employees will affect their performance on some way.

As such, the study focuses on the following problem statement.

\section{What is the impact of employees' Emotional Resilience on the Employees Work Performance of the executives in Private Sector Organizations in Sri Lanka?}

\section{Objectives of the Study}

- To assess the impact of emotional resilience on employees' work performance.
- To assess the relationship between emotional resilience of the employees and their performances.

- To explore the notional identification relating to the current research study.

- To identify the factors affecting to the emotional resilience and employees' work performance.

\section{Literature Review}

It is obvious that the world has become more competitive and organizations strive to obtain a larger output with fewer workers while embracing sophisticated technology. The consequence of this situation is considerably negative where it places the employees to experience high level of stress and it has created an unnecessary cost to the companies when protecting employees from the stress related injuries. Apart from that, job dissatisfaction, absenteeism, employee turnover, lost time because of the mental and physical injuries and declining the overall productivity will also be some of the adverse conditions that the companies have to tolerate and the related cost associated is not less than $45 \%$ of the company's operating profit (Winwood, McEwen, \& Colon, 2013). Therefore, the companies currently focus more on the individuals who can effectively deal with the stress and who can quickly recover. This special ability is known as emotional resilience where the companies try to build the capacity of employees to be more resilient as it generates a positive impact on job satisfaction, engagement, commitment and their performances (Resilience in Organizations, 2011). 


\section{Employee Performance}

The human resource function's effectiveness depends on the extent of the performances of the employees (Pradhan \& Jena, 2016). Employee performance is the key factor that enhances the overall organizational productivity (Bommer et al., 1995; Lawler \& Worley, 2006; Schiemann, 2009, as cited in Pradhan \& Jena, 2016) and the efficiency (Van Vuuren and Elving, 2008 as cited in Gupta \& Sharma, 2018). Rivai (2004) stated that the standards, criteria or the targets that have been given for a person in advance to accomplish and the extent to which he successfully achieves them shows his contribution in terms of performance. Moreover, he stated that the skill, abilities, and traits of a person affect an employee's performance which is supported by the desires of a person and the environment. The high achievers are the key to accomplish the success for the today's business organizations (as cited in Pawirosumarto, Sarjana \& Muchtar, 2017). Moreover, feedback for the performance is mandatory to ensure the quality. Therefore, the objective performance assessments are being used for the purpose of giving comments to increase the productivity and the performance. Furthermore, the key performance indicators and the key performance indexes are some forms of performance assessments that can be used to enhance the individual contributions (Pawirosumarto, Sarjana, \& Muchtar, 2017).

\section{Emotional Resilience}

Shin, Taylor and Seo (2012) defined the resilience as an ability to recover quickly from disruptions in functioning (as cited in Bardoel et al., 2014). It is the capacity of the individuals to quickly recover, bounce back or cope successfully in response to the adversity or uncertainty (Resilience in Organizations, 2011). Some explanations have stated that the resilience is a personality trait (Winwood, McEwen, \& Colon, 2013). Bernard (2016) said that in order to encourage the successful interactions, people need to have the ability to adapt in front of the stressful situations. And being more bendable, well-balanced and the awareness of how to handle one's emotions in a productive and a constructive manner are some of the important characteristics of a resilient individual (as cited in Rauschenbach \& Goritz, 2012). People will have to experience trauma, acute or chronic situations and the ability to adapt productively can be identified as emotional resilience (Feder, Nestler, \& Charney, 2009). Moreover, Masten and Coatsworth (1998) defined resilience as "manifested competence in the context of significant challenges to adaptation or development" and according to Luthar and Ziglar (1991) it is important to have a successful navigation of the self in traumatic situations (as cited in Crawford, 2006).Considering all these factors, obtaining the effective individuals and selecting the best ones is significant especially in adverse instances (Seville, 2018).

Shin, Taylor and Seo (2012) emphasized that, compared to the nonresilient individuals; the resilient employees will be able to recover more promptly (as cited in Tonkin et al., 2018). They have the positive emotions which are promoted by flexible 
thinking, adaptability, broadened focus and decreased-autonomic actions. A study of neurological aspect of emotional resilience pointed out that the biological responses of a person in face of stressful situations will be affected by genes. Moreover, the acute psychobiological responses to the stress related incidents are involved with neuro-peptides, numerous hormones and neurotransmitters (Feder, Nestler, \& Charney, 2009). Furthermore, the individual resilience is also affected by many factors such as personality traits, emotional intelligence, self-efficacy, selfconfident, self-esteem, internal locus of control, adapting coping strategies with problem solving abilities, flexibility, resourcefulness, and healthy relationships (Resilience in Organizations, 2011). Level of resilience can be differing from person to person, basically with the age. According to Gross et al. (1997) and Lawton et al. (1992) the particular skills as if emotional responses and regulations are increasing with the age (as cited in Rauschenbach \& Goritz, 2012). When it comes to work place, Kuntz et al., (2016) indicated that the resilience is being facilitated and affected by organizational practices as if association in face of challenges and learning from mistakes, the supportive organizational culture that provides necessary resources to perform the job and assist to nurture the resilient behaviors (as cited in Tonkin et al., 2018). Most of the organizations have implemented Critical Incidents Stress Management (CISM) Programs as well for the employees in assisting them to deal with the stress related events (Freeman \& Carson, 2006). Organizations nowadays try to build a resilient workforce as it has a positive impact on overall productivity and innovations and employees try to retain with the organization because of the high level of job satisfaction and the engagement. Furthermore, the burnout and stress related claims will be decreased (Resilience in Organizations, 2011).

Notional identification relating to the emotional resilience should be considered as well (Bardoel et al., 2014). According to Luthans (2002) the concept of resilience has rooted in the fields of positive psychology and positive organizational behavior. Positive human behaviors and psychological capacities are the core factors which are embedded in the positive organizational behavior that affects directly to the performance. Furthermore, according to Luthans, Youssef, and Avolio (2007) it encompasses self-efficacy, optimism, hope and resilience. They are the key features of the concept of psychological capital. The view behind this concept includes a series of efforts made by a person and the results of those efforts that endorse resilience. Luthans et al. (2006) emphasized that (as cited in Bardoel et al., 2014) most of the companies nowadays implement number of proactive and reactive HR practices that encourage the resilience in order to nurture the psychological capital. The employee assistance programs and the counseling facilities for the family losses are some of the examples for reactive resilienceenhancing HR practices. Furthermore, Shin, Taylor and Seo (2012) pointed out the theory of conservation of resources, which was developed by Hobfoll (1989). The theory argued that 
the resilience is a resource that can be developed. Not only to reduce the stress, but also to assist the employees' dedication to change. And the employee performance and organizational performance should be supported by this particular resource. Theory further states that, people try to obtain, retain, and protect the resources. Resources can be categorized in to three types. They are instrumental, social and psychological resources. People will have to face for an acute impact in front of the resource loss than a resource gain (as cited in Bardoel et al., 2014). The theory also emphasized the proactive resilience, which enhancing HR practices and highlights the importance of employee involvement. Hence, the theory of positive psychology and the conservation of resources provide an insight about the practices that can be implemented in order to enhance the level of resilience (Bardoel et al., 2014).
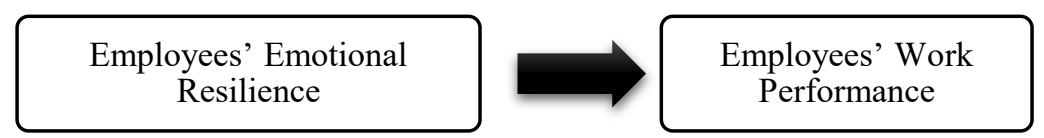

Figure 01: Conceptual Framework of the Study

Source: Authors, 2018

\section{Hypotheses of the Study}

As such, the hypotheses can be advanced as,

H1a: $=$ There is a significant relationship between the Employees'

Emotional Resilience and the

Employees' Work Performance of the
Kuntz et al., (2016) indicated that supportive organizational environment is an essential contributor that improves the resilience (as cited in Tonkin et al., 2018). Companies try to enhance the level of resilience of the employees in order to foster the general well-being while trying to improve the immediate work experiences of the employees that improves their current performance. Moreover, they try to deploy them with relevant skills and strategies to face the future challenges and uncertainties (Resilience in Organizations, 2011).

\section{Conceptual Framework}

The conceptual framework of the current research study is illustrated in figure 01assuming that the other factors are remaining constant. The study has considered the employees' emotional resilience as the independent variable and the employees' work performance as the dependent variable. The hypothesized relationship among the variables has illustrated in the same figure. 


\section{Overall Research Design}

The study is a quantitative study in nature that attempts to find out the answer for the above mentioned research problem. Since the study tries to test the formulated hypotheses in this research model, the research work is launched as an explanatory study, which focuses on to investigate the relationship and the impact between employee resilience and employee performance. And it is important to highlight that, even though the situation was well examined in European and US contexts, there is no any clear-cut academic demonstration that convey the relationship and the impact of these two variables within the Sri Lankan context. The previously mentioned examples were extracted from the Australian and US business sectors. Therefore, it is important to test the variables pertaining to the executive level employees in Sri Lanka's private sector. Furthermore, as the study is carried out as a quantitative research work, descriptive statistical techniques were used in general such as mean, mode, variation, and standard deviation. Most importantly, the correlation and regression were computed in order to ensure the validation of the determinants. The study is a cross-sectional study as the information gathered only in a specific time and it does not repeat. Apart from that, the researcher's obstructions will be least in the present investigation. Unit of examination will be at the individual level: executive level employees in private sector. The sample encompasses 74 employees and the simple random sampling technique has been used. Data collected through a questionnaire and the examined with
SPSS. Frequency analysis, correlation test and regression analysis were used to analyze data and to test the developed hypotheses.

\section{Population}

Population of the current research study includes the executive level employees in Sri Lanka's private sector. Therefore, the total population of the current empirical study is unknown.

\section{Sample and Sampling Technique}

Simple random sampling technique has used as the sampling technique to select the representative sample. The method has chosen on the basis of personnel judgment or convenience. 74 employees were selected randomly from a selected company for the sample. As the researcher can approach more respondents and as it provides a better representative, the simple random sampling technique has considered as more reliable.

\section{Sample Composition}

The current researcher has identified a sample which consists of 74 respondents. 74 questionnaires were distributed among the participants and only 70 questionnaires were filled and returned. Hence, the current study has a $94.6 \%$ of a response rate approximately. This provides a positive insight about the study as it could able to capture nearly $100 \%$ of the sample. When it comes to the gender composition of the sample, $70 \%$ consists of male employees and 30\% consists of female employees. From the sample, $64.3 \%$ of employees are married and $35.7 \%$ of employees are single when consider about the marital status. Furthermore, the age 
composition of the sample should also be considered. Majority of the sample belongs to the age category of 25 years - 35 years where it was reported as $58.6 \%$ as a percentage. $1.4 \%$ of employees represented the categories of 45 years - 55 years and above 55 years. $28.6 \%$ represented the 35 years 45 years category and $10 \%$ of the sample represented the 18 years - 25 years category. Moreover, the years of experience depicted that $57.1 \%$ of employees have more than 05 years work experience and $20 \%$ of the sample are having 03 years - 05 years work experience. $14.3 \%$ of the sample is having 02 years -03 years experience. $7.1 \%$ of the employees in the sample are having 01 years - 02 years work experience whereas $1.4 \%$ of employees are having less than 01 year work experience.

It is important to consider about the designation (Level) composition of the sample as well. Majority of the employees belong to the executive category and it is $45.7 \%$ of the sample. $4.3 \%$ of the employees are in the senior manager category and it can be identified as the lowest percentage under this category. $15.7 \%$ of the sample belongs to the senior executive level. The assistant manager and manager category represented $17.1 \%$ by each category.

\section{Testing of Hypotheses}

Correlation and Regression were used to test the hypotheses where the employees' work performance and resilience were assessed using bivariate correlation and Pearson's correlation coefficient.

H1a: $=$ There is a significant relationship between the Employees' Emotional Resilience and the Employees' Work Performance of the Executives in selected Private Sector organizations in Sri Lanka.

Table 1: Correlations

\begin{tabular}{|l|l|l|l|}
\hline \multicolumn{2}{|c|}{} & \multicolumn{1}{|c|}{$\begin{array}{c}\text { Employees Work } \\
\text { Performance }\end{array}$} & \multicolumn{1}{|c|}{$\begin{array}{c}\text { Employee } \\
\text { Resilience }\end{array}$} \\
\hline \begin{tabular}{l} 
Employees \\
\multirow{2}{*}{$\begin{array}{l}\text { Work } \\
\text { Performance }\end{array}$}
\end{tabular} & Pearson Correlation & 1 & $.494^{* *}$ \\
\cline { 2 - 4 } & Sig. (2-tailed) & & .000 \\
\cline { 2 - 4 } & $\mathrm{N}$ & 70 & 70 \\
\hline $\begin{array}{l}\text { Employee } \\
\text { Resilience }\end{array}$ & Pearson Correlation & $.494^{* *}$ & 1 \\
\cline { 2 - 4 } & Sig. (2-tailed) & .000 & 70 \\
\cline { 2 - 4 } & $\mathrm{N}$ & 70 & \\
\hline
\end{tabular}

**. Correlation is significant at the 0.01 level (2-tailed).

Source: Survey Data, 2018 
The Pearson correlation is 0.494 , which is close to 0.5 , and it is suggesting that there is a moderate positive correlation between the emotional resilience and the employee performance. The correlation of 0.494 is statistically significant. Therefore, the current researcher has proven that there is a significant relationship between the employee performance and the emotional resilience. Correlation coefficient is significant at the 0.01 level. Pearson correlation gives an insight about; there is a significant moderate positive relationship between emotional resilience and employee performance. Hence, H1 hypothesis was accepted while rejecting the null hypothesis. In order to test the second hypothesis, the simple regression has been calculated.

H1b: = There is a significant impact comes from the Employees' Emotional Resilience on the Employees' Work Performance of the Executive level employees in selected Private Sector organizations, Sri Lanka.

Table 2: Model Summary

\begin{tabular}{|l|l|l|l|l|}
\hline \multicolumn{1}{|c|}{ Model } & \multicolumn{1}{|c|}{$\mathrm{R}$} & \multicolumn{1}{|c|}{ R Square } & \multicolumn{1}{|c|}{$\begin{array}{c}\text { Adjusted R } \\
\text { Square }\end{array}$} & $\begin{array}{l}\text { Std. Error of } \\
\text { the Estimate }\end{array}$ \\
\hline 1 & $.494^{\mathrm{a}}$ & .244 & .233 & .44097 \\
\hline \multicolumn{2}{|l}{ a. Predictors: (Constant), Employee Resilience } \\
\hline
\end{tabular}

Source: Survey Data, 2018

According to the simple regression analysis, the model summary provides an insight about the extent to which the

According to the table 2 of model summary, the R-value represents the relationship between the dependent and independent variable. The $\mathrm{R}$ square is 0.244 and it represents the impact comes from the independent variable on dependent variable. Therefore, employee resilience has $24.4 \%$ of an impact on employee performance while the rest of the $75.6 \%(100 \%-24.4 \%)$ is explained by other causes that influence employees' performance.

According to the study, the emotional resilience has a significant positive weak impact on the employee performance and the impact is $24.4 \%$ as a percentage. Thus, hypothesis two independent variable of the emotional resilience effects on the dependent variable of the employee performance

$\mathrm{H} 1 \mathrm{~b}$ has been accepted as well based on above figures. Therefore, the regression equation can be obtained as follows,

$\mathbf{Y}=\mathbf{m X}+\mathbf{C}+\mathbf{E}$

$\mathrm{Y}=$ Employees’ Work Performance,

$\mathrm{X}=$ Employee Resilience,

$\mathcal{E}=$ Standard error

\section{Employees' Work Performance $=$ $1.432+0.647$ Employee Resilience + 0.138}

It is visible that the statistical data supports the first hypothesis (H1a: = 
There is a significant relationship between the Employees' Emotional Resilience and the Employees' Work Performance of the Executive level employees in selected Private Sector organizations, Sri Lanka) as there is a significant moderate positive relationship between these two variables. And the data support the second hypothesis $(\mathrm{H} 1 \mathrm{~b}$ : $=$ There is a significant impact comes from the Employees' Emotional Resilience on the Employees' Work Performance of the Executive level employees in selected Private Sector organization, Sri Lanka) as well since there is a significant positive weak impact on employee performance from emotional resilience.

\section{Discussion of Findings}

The study aimed to identify the relationship exists between the emotional resilience and the employee performance and how does the emotional resilience affect the employee performance. According to Youssef and Luthans (2007) the resilient individuals will invest the time, resources, and energy in order to bounce back from the situation after recognizing the adverse circumstances and their impact effectively (as cited in Bardoel et al., 2014). Outcomes of high resilient individuals tend to contribute positively to the organization because of the high level of job satisfaction. Because of this, the productivity is increasing. Hence the employee performance affects positively (Resilience in Organizations, 2011).Previous researches have emphasized that the consequences of the lack of resilience. Unnecessary cost will be increased because of the stress related matters, retention problems and increase the turnover, feel the sense of helplessness and guilt and psychological issues are some of the examples (Resilience in Organizations, 2011).

The current research study has focused on the executive level employees in Sri Lanka's private sector as the population. According to the statistically generated results, the Pearson correlation was reported as 0.494 and it can be concluded that there is a significant moderate positive relationship between emotional resilience and employee performance. Moreover, $24.4 \%$ of an impact comes from the emotional resilience on the employee performance. Furthermore, the current researcher emphasized that $75.6 \%$ of an impact comes from the factors other than the emotional resilience.

\section{Implications}

Changing needs of the business environment has created an increasing demand to have efficient and effective employees. Employees are the backbone for a company. Organizations try to obtain productive employees, who can effectively deal with environmental challenges and changes. Therefore, the people serve as a major strength that assists to ensure the survival of the company. Rather than having just people at the workplace, having a resilient workforce has taken a growing importance within the business sector. Resilience will enhance the employee satisfaction and overall productivity that ultimately enhances the overall organizational profitability. In addition, the employee retention would be increased. Just in case if the employees are unable to 
recover quickly, it will create a negative impact on the companies' effectiveness. Therefore, the organizations should consider about the emotional resilience level of the employees properly. As emphasized, there is $75.6 \%$ of an impact comes from the factors apart from the resilience. Managers should consider those factors as well. It is advisable for the managers to use more resilience enhancing HR practices for the employees. This will help them to manage the stressful circumstances effectively. Employers can improve the practices as if implementing counseling and the mentoring facilities to help employees to deal with the hard situations. Employees are responsible to create a proper balance between their work and life. In assisting this, managers should give small and sensible targets for employees to achieve. Executing employee assistance programs, managing cultural differences effectively within the organization, providing flexible work schedules, and creating a supportive work environment system are some of the practices that affect positively towards the emotional resilience.

\section{Recommendations}

Current researcher has identified the recommendations in two main categories:

Individual level: The findings of the current research study provide a wise insight for the individuals to get to know about the benefits of being more resilient. Especially when applying for the jobs, if they know about their resilience level, they will be able to accept even a challenging job. Even so, working under pressure is not particularly attractive to someone, and then the person can apply for a less challenging job. Moreover, it is important to improve this particular quality of resilience as much as they can since it will be beneficial not only for their work, but also for their personal life as well.

Organizational level: On the other hand, it is better if the organizations can consider the resilience level of the candidates who have applied for job vacancies especially in relation to the scope and the other related requirements of the job. If the companies have a mechanism to identify the level of resilience at the time of the interview, they will be able to hire the resilient candidates for the jobs with more responsibilities.

In addition, companies should implement the resilience-enhancing practices as well.

\section{Limitations}

The main limitation of the current research study is the availability of some other factors affecting employee performance other than the resilience, but the current researcher has considered only the concept of resilience. Moreover, another limitation arose when selecting the sample. The current researcher had to limit only for a certain number of participants and a company collected the sample data, which is located in the western province in Sri Lanka. The attitudes of the employees can be influenced by certain environmental factors as well. Furthermore, the sample encompasses the majority of the executive level employees compared to the senior manager and above category. 


\section{Conclusion}

The main objective of this research study was to identify the extent to which the employee work performances were affected by the emotional resilience. According to the study, the current researcher could able to find that the employee performance is being affected by emotional resilience. In addition, the Pearson coefficient was recorded as 0.494 that shows a moderate positive correlation and it was depicted that there is a $24.4 \%$ of an impact comes from resilience of the employees towards their performance and the rest of the impact is coming from the other factors and it is $75.6 \%$ as a percentage. Finally, it can be concluded that the employee resilience is a significant factor that affect the employees' performances, which carried a least attention, but still it has a huge significance to the organizations in assisting the employees to recover quickly from the adverse situations. The current researcher has achieved the general and the specific objectives successfully and the answers for the research questions have been found properly.

\section{Suggestions for Future Research}

The theories of positive psychology and the conservation of resources emphasized the importance of implementing HR practices that helps to enhance the resilience level of the workers and these practices help to obtain the positive outcomes from the employees (Bardoel et al., 2014). Hence, it is important to study further about the mechanisms or the practices that can be used at the time of the interviews when selecting the candidates for the jobs that contain unbearable responsibilities. Furthermore, the gender and the age can also be critical when hiring a person to an organization. Some of the studies have identified that; the genetic influence also can be a reason for most of the biological responses including resilience (Feder, Nestler, \& Charney, 2009). Thus, further researches are needed in order to find the association between neurological aspects of emotional resilience and how does it affect the gender and the age of a person.

\section{References}

Bardoel, E. A., Pettit, T. M., Cieri, H. D., \& McMillan, L. (2014). Employee resilience: an emerging challenge for HRM. Asia Pacific Journal of Human Resources, 279-297.

Crawford, K. M. (2006). Risk and protective factors related to resilience in adolescents in an alternative education program. Graduate Theses and Dissertations, 1177.

Feder, A., Nestler, E. J., \& Charney, D. S. (2009). Psychobiology and molecular genetics of resilience. New York: Macmillan Publishers Limited.

Freeman, D. G., \& Carson, M. (2006). Developing Workplace Resilience. Workplace Behavioral Health, 113-121. 
Gupta, N., \& Sharma, V. (2018). Relationship between leader member exchange (LMX), high-involvement HRP and employee resilience on extra-role performance: Mediating role employee engagement. Journal of Indian Business Research, 26-150.

Pawirosumarto, S., Sarjana, P. K., \& Muchtar, M. (2017). Factors affecting employee performance of PT.Kiyokuni Indonesia. International Journal of Law and Management, 602-614.

Pradhan, R. K., \& Jena, L. K. (2016). Employee Performance at Workplace: Conceptual Model and Empirical Validation. SAGE Publications, 1-18.

Rauschenbach, C., \& Goritz, A. S. (2012). Age Stereotypes about Emotional Resilience at Work. Educational Gerontology, 511-519.

Resilience in Organizations. (2011). Illuminations e- Magazine, 1-28.

Seville, E. (2018). Building resilience: how to have a positive impact at the organizational and individual employee level. Development and Learning in Organizations: An International Journal, 15-18.

Tonkin, K., Malinen, S., Näswall, K., \& Kuntz, J. C. (2018). Building employee resilience through wellbeing in organizations. Human Resource Dev Quarterly, 107-124.

Winwood, P., McEwen, K., \& Colon, R. (2013). A Practical Measure of Workplace Resilience. Occupational and Environmental Medicine, 1205-1212. 